\title{
Usefulness of scoring right ventricular function for assessment of prognostic factors in patients with chronic thromboembolic pulmonary hypertension
}

\author{
Yoshihiro Kamimura ${ }^{1} \cdot$ Naoki Okumura $^{2}$. Shiro Adachi ${ }^{2} \cdot$ Shigetake Shimokata ${ }^{1} \cdot$ Fumitaka Tajima $^{1}$. \\ Yoshihisa Nakano ${ }^{1} \cdot$ Akihiro Hirashiki $^{3} \cdot$ Toyoaki Murohara $^{1} \cdot$ Takahisa Kondo $^{2}$
}

Received: 21 November 2017 / Accepted: 20 April 2018 / Published online: 27 April 2018

(c) The Author(s) 2018

\begin{abstract}
Right ventricular (RV) function is associated with prognosis in chronic thromboembolic pulmonary hypertension (CTEPH). This study aimed to establish an RV dysfunction score using RV echocardiographic parameters to clarify the clinical characteristics in patients with CTEPH and to compare RV dysfunction score with parameters such as World Health Organization (WHO) functional class, hemodynamics, exercise capacity, and plasma BNP level. We enrolled 35 inpatients with CTEPH (mean age, $62 \pm 15$ years, 15 males). We constructed 'an RV dysfunction score' calculated as the summation of each point awarded for the presence of four parameters: tricuspid annular plane systolic excursion (TAPSE) $<16 \mathrm{~mm}, 1$ point; tissue Doppler-derived tricuspid lateral annular systolic velocity $\left(S^{\prime}\right)<10 \mathrm{~cm} / \mathrm{s}, 1$ point; right ventricular fractional area change $(\mathrm{RVFAC})<35 \%, 1$ point; and right ventricular myocardial performance index (RV-MPI) $>0.4,1$ point. TAPSE, $S^{\prime}$, RVFAC, and RV-MPI was $18.7 \pm 4.8 \mathrm{~mm}, 11.9 \pm 3.1 \mathrm{~cm} / \mathrm{s}, 33.5 \pm 13.9 \%$, and $0.39 \pm 0.2$, respectively. The RV dysfunction score was associated with symptom [WHO functional class $(p=0.026)$ ], hemodynamics [mean PAP $(p=0.01)$, cardiac index $(p=0.009)$, pulmonary vascular resistance $(p=0.001)$, and $\mathrm{SvO}_{2}(p=0.039)$ ], exercise capacity [6-min walk distance $(p=0.046)$, peakVO $2(p=0.016)$, and $\mathrm{VE} / \mathrm{VCO}_{2}$ slope $\left.(p=0.031)\right]$, and plasma BNP level $(p=0.005)$. This $\mathrm{RV}$ dysfunction score using the four RV echocardiographic parameters could be a simple and useful scoring system to evaluate prognostic factors in patients with CTEPH.
\end{abstract}

Keywords Chronic thromboembolic pulmonary hypertension $\cdot$ Echocardiography $\cdot$ Right ventricular function

Electronic supplementary material The online version of this article (https://doi.org/10.1007/s00380-018-1168-7) contains supplementary material, which is available to authorized users.

Takahisa Kondo

takahisa@med.nagoya-u.ac.jp

1 Nagoya University Graduate School of Medicine, 65 Tsurumai-cho, Shouwa-ku, Nagoya 466-8550, Japan

2 Department of Advanced Medicine in Cardiopulmonary Disease, Nagoya University Graduate School of Medicine, 65 Tsurumai-cho, Shouwa-ku, Nagoya 466-8560, Japan

3 Department of Cardiology, National Center for Geriatrics and Gerontology, Morioka-cho 7-430, Obu 474-8511, Japan

\section{Introduction}

Chronic thromboembolic pulmonary hypertension (CTEPH) continues to be a disease with poor prognosis, although several specific drugs and treatment are available [1,2]. Echocardiography is widely used for assessing the severity of pulmonary hypertension and right ventricular (RV) function, which is important for prognosis in patients with CTEPH. The American Society of Echocardiography (ASE) recommends four RV echocardiographic parameters for the assessment of RV function: tricuspid annular plane systolic excursion (TAPSE), tissue Doppler-derived tricuspid lateral annular systolic velocity $\left(S^{\prime}\right)$, right ventricular fractional area change (RVFAC), and right ventricular myocardial performance index (RV-MPI) [3-7]. However, there is still discussion regarding which echocardiographic parameter is best associated with RV function, and also is capable of predicting outcome. RV has a unique and complicated contraction 
pattern: [8-10] Hence, RV function needs to be assessed comprehensively. We hypothesized that RV function could be evaluated more precisely if the four RV echocardiographic parameters were combined.

This study aimed to establish an RV dysfunction score using the four RV echocardiographic parameters (TAPSE, $S^{\prime}$, RVFAC, and RV-MPI) to clarify the clinical characteristics on admission in patients with CTEPH and to compare the $\mathrm{RV}$ dysfunction score with parameters such as symptoms of World Health Organization (WHO) functional class, hemodynamics, exercise capacity [6-min walk test (6MWT) and cardiopulmonary exercise test (CPET)], and plasma brain natriuretic peptide (BNP) level used for risk assessment in patents with CTEPH.

\section{Materials and methods}

\section{Study individuals}

We enrolled 35 consecutive patients with CTEPH admitted to our institution between April 1, 2015 and Aug 31, 2017. CTEPH was diagnosed as a mean pulmonary arterial pressure (PAP) of $\geq 25 \mathrm{mmHg}$ and a pulmonary arterial wedge pressure (PAWP) of $<15 \mathrm{mmHg}$ by right heart catheterization (RHC), ventilation-perfusion lung scintigraphy, computerized tomography, and/or pulmonary angiography after at least 3 months anticoagulant treatment. Pregnancy, hypersensitivities to the contrast medium, and renal dysfunction were excluded. This study was approved by the human research ethics committees of Nagoya University Hospital (no. 2014-0332), and all patients gave written informed consent.

\section{Doppler echocardiography}

Two-dimensional, M-mode, and Doppler echocardiographic images were acquired (iE33; Philips Healthcare, Eindhoven, the Netherlands) and examined in accordance with the ASE guidelines [6]. Patients were examined in the left decubitus position through parasternal long-axis, short-axis, and apical views. TAPSE was measured with M-mode imaging as the distance of systolic excursion of the lateral tricuspid valve annular segment along its longitudinal plane from the RV-focused apical 4-chamber window. Tissue Doppler echocardiography was performed in the RV-focused apical four-chamber view, with the tissue sampling volume located at the lateral side of the tricuspid annulus, and the $S^{\prime}$ was measured. The percentage RVFAC was defined as (end diastolic area - end systolic area)/end diastolic area $\times 100$. RVMPI was defined as the ratio of isovolumic time divided by ejection time.

\section{Hemodynamic studies}

All patients underwent RHC via the right internal jugular vein with a 6-French Thermodilution catheter (Goodman Co. Ltd., Nagoya, Japan) to obtain the PAP, PAWP, RV pressure (RVP), and right atrial pressure (RAP). Mixed venous oxygen saturation $\left(\mathrm{SvO}_{2}\right)$ and arterial oxygen saturation $\left(\mathrm{SaO}_{2}\right)$ were measured in blood drawn from the main pulmonary artery and radial artery, respectively. Cardiac output (CO) was calculated by using the Fick method, and pulmonary vascular resistance (PVR) was calculated by using the standard formula: PVR $=($ mean PAP - mean PAWP $) /$ CO. Cardiac index (CI) was calculated by using the formula: $\mathrm{CI}=\mathrm{CO} /$ body surface area.

\section{Six-minute walk test}

The measurement of 6-min walk distance (6MWD) was performed in all but one patients enrolled in this study. Each patient was instructed to walk at their own pace. The physiotherapist supervised the test, telling the patient the elapsed time every $1 \mathrm{~min}$. Although the patient was allowed to stop and take a rest freely, all patients continued to walk during the test. No patients were terminated prematurely by the test administrator, and no complications occurred. Dyspnea during the test was checked with the modified Borg dyspnea score. Before and during the 6MWT, the peripheral capillary oxygen saturation $\left(\mathrm{SpO}_{2}\right)$ was monitored by saturation monitoring for the safety.

\section{Cardiopulmonary exercise testing}

Cardiopulmonary exercise testing (CPET) was performed in all patients in an erect position on an electronically braked cycle ergometer with breath-by-breath measurements by using an Ergospirometry Oxycon Pro (Carefusion Germany, 234, GmbH, Hochberg, Germany). The exercise protocol consisted of $3 \mathrm{~min}$ of rest and $3 \mathrm{~min}$ of unloaded cycling, followed by a $10-\mathrm{W} / \mathrm{min}$ ramp-incremental protocol. Parameters including oxygen consumption $\left(\mathrm{VO}_{2}\right)$, carbon dioxide output $\left(\mathrm{VCO}_{2}\right)$, and the minute ventilation (VE) were continuously measured by a fixed cardio-pulmonary exercise system through a tightly fitted facemask. The CPET was safely performed without any problem such as syncope, arrhythmia, or worsening of right heart failure.

\section{Right ventricular dysfunction score}

The RV dysfunction score was calculated as the summation of points awarded for the presence of four parameters (TAPSE $<16 \mathrm{~mm}, 1$ point; $S^{\prime}<10 \mathrm{~cm} / \mathrm{s}, 1$ point; 
RVFAC $<35 \%, 1$ point; and RV-MPI $>0.4,1$ point) using the cut-off value recommended by ASE guidelines [6]. Total scores range from 0 to 4 . Patients were then divided into four groups based on their score: score $0(n=6)$, score $1(n=13)$, score $2(n=11)$, and score $3 / 4(n=5)$. Higher score indicates worse RV function.

\section{Statistical analysis}

All analyses were performed using Stata version 14 (Stata Corp., College Station, Texas, USA). Baseline characteristics were compared using the Kruskal-Wallis test for continuous variables and the $\chi^{2}$ test for categorical variables. Hemodynamics, exercise capacity, and plasma BNP level between the four RV function parameters were compared using the Wilcoxon rank sum test. Trend test was performed among the four RV dysfunction score groups. All reported $p$ values were two-sided, and $p<0.05$ was considered to be statistically significant.

\section{Results}

Table 1 shows the baseline patients' characteristics according to the RV dysfunction score. Overall, the mean age of all patients was $62 \pm 15$ years, and $15(43 \%)$ were male. Of these 35 patients, 21 (60\%) were receiving oral CTEPHspecific drug therapy, riociguat, prescribed at our hospital. The mean PAP, PVR, CI, and RAP of all 35 patients were $37.2 \pm 10.6 \mathrm{mmHg}, 8.2 \pm 4.7$ Wood Unit, $2.3 \pm 0.71 / \mathrm{min} /$ $\mathrm{m}^{2}$, and $6.0 \pm 3.0 \mathrm{mmHg}$, respectively. All patients were prescribed anticoagulation, such as warfarin or direct oral anticoagulants. There were no statistically significant differences between four groups in the laboratory findings and pericardial effusion.

Figure 1 shows a comparison of the hemodynamics (mean PAP, CI, PVR, RAP, and $\mathrm{SvO}_{2}$ ) according to the RV dysfunction score. The mean PAP, CI, PVR, and $\mathrm{SvO}_{2}$ were significantly worsening as the RV dysfunction score increased ( $\mathrm{p}$ for trend $=0.01, p$ for trend $=0.009, p$ for trend $=0.001$, and $p$ for trend $=0.039$, respectively). The RAP showed a considerable trend toward significance $(p=0.062)$.

Figure 2 shows a comparison of the exercise capacity (6MWD, peakVO $\mathrm{MO}_{2}$, and $\mathrm{VE} / \mathrm{VCO}_{2}$ slope), symptom (WHO functional class), and plasma BNP level according to RV dysfunction score. All parameters showed significant deteriorating trend as the $\mathrm{RV}$ function score increased ( $p$ for trend $=0.046, p$ for trend $=0.016, p$ for trend $=0.026$, and $p$ for trend $=0.005$, respectively).

Table 2 shows the comparison of the baseline hemodynamics, exercise capacity, and plasma BNP levels between the four echocardiographic parameters: TAPSE $(\geq 16$ vs. $<16), S^{\prime}(\geq 10$ vs. $<10)$, RVFAC ( $\geq 35$ vs. $\left.<35\right)$, and
RV-MPI ( $\leq 0.4$ vs. $>0.4$ ). Of these parameters, the correlations between RV-MPI/RVFAC and hemodynamics was stronger than those between TAPSE/ $S^{\prime}$ and hemodynamics. Especially, RVFAC ( $\geq 35$ vs. $<35$ ) showed the strongest correlation with hemodynamics (mean PAP, $32.7 \pm 8.6$ vs. $41.5 \pm 10.7 \mathrm{mmHg}, p=0.012$; PVR, $5.8 \pm 2.5$ vs. $10.5 \pm 5.3$ Wood Unit, $p=0.002$; CI, $2.7 \pm 0.7$ vs. $2.0 \pm 0.51 / \mathrm{min} / \mathrm{m}^{2}$, $p=0.003$; RAP, $5.1 \pm 2.6$ vs. $6.9 \pm 3.1 \mathrm{mmHg}, p=0.068$; and $\mathrm{SvO}_{2}, 67.3 \pm 6.0$ vs. $58.8 \pm 9.2 \%, p=0.003$, respectively). RVFAC also tends to show stronger correlation with exercise capacity and laboratory findings than the other parameters. Since there is a possibility that riociguat positively affected $\mathrm{RV}$ function and hemodynamics, sub-group analysis was conducted between the patients with riociguat and without riociguat (Supplementary Table 1). The result showed no significant difference between these two groups. Therefore, we concluded that treating two groups of patients collectively was appraisable. Table 3 shows the correlations among the four RV function echo parameters. Of these four parameters, there were significant correlations between TAPSE and $S^{\prime}$, and between RVFAC and RV-MPI $(r=0.603$, $p<0.001$, and $r=-0.461, p=0.005$, respectively).

\section{Discussion}

In the present study, we demonstrated that our simple RV dysfunction score using four important RV echocardiographic parameters (TAPSE $<16 \mathrm{~mm}, S^{\prime}<10 \mathrm{~cm} / \mathrm{s}$, RVFAC $<35 \%$, and RV-MPI $>0.4$ ) was useful for risk assessment in CTEPH patients in terms of symptoms (WHO functional class), hemodynamics, exercise capacity (6MWT and CPET) and plasma BNP level. Patients with a higher RV dysfunction score had higher BNP levels, more impaired exercise capacity, and worse hemodynamics.

$\mathrm{RV}$ function is the most important determinant of prognosis in patients with pulmonary hypertension including CTEPH [11-13]. Cardiac magnetic resonance imaging (MRI) and multi detective computed tomography can be used to assess RV function such as RV volumes, mass, and thickness, and provides accurate and reproducible measurements of RV function. Especially, cardiac MRI is currently regarded as the "gold standard" for RV function assessment [14-16]. Although MRI has the advantage of enabling functional cardiac assessment without the need for contrast media injection or exposing patients to radiation, the main drawbacks include high expenses involved, long examination times, problems of claustrophobia, and limited use for patients with device implantations. In contrast, echocardiography remains to be the first-line examination modality for assessing RV function because of less cost, easy availability, and repeatability [17, 18] Additionally, several studies reported that there was a good association between 
Table 1 Patients' characteristics according to the RV dysfunction score

\begin{tabular}{|c|c|c|c|c|c|c|}
\hline & \multirow{2}{*}{$\begin{array}{l}\text { Overall } \\
(n=35)\end{array}$} & \multicolumn{4}{|c|}{ RV dysfunction score } & \multirow[t]{2}{*}{$p$ value } \\
\hline & & $\begin{array}{l}0 \\
(n=6)\end{array}$ & $\begin{array}{l}1 \\
(n=13)\end{array}$ & $\begin{array}{l}2 \\
(n=11)\end{array}$ & $\begin{array}{l}3 / 4 \\
(n=5)\end{array}$ & \\
\hline Age (years) & $62.0 \pm 14.7$ & $59.7 \pm 13.0$ & $64.5 \pm 14.3$ & $60.1 \pm 17.0$ & $62.6 \pm 15.9$ & 0.761 \\
\hline Male & $15(42.9 \%)$ & $2(33.3 \%)$ & $5(38.5 \%)$ & $5(45.5 \%)$ & $3(60.0 \%)$ & 0.812 \\
\hline BMI $\left(\mathrm{kg} / \mathrm{m}^{2}\right)$ & $24.6 \pm 5.9$ & $24.0 \pm 4.2$ & $25.3 \pm 4.3$ & $23.6 \pm 4.7$ & $23.0 \pm 2.3$ & 0.422 \\
\hline $\mathrm{SBP}(\mathrm{mmHg})$ & $118.9 \pm 23.5$ & $120.4 \pm 33.1$ & $107.5 \pm 14.0$ & $116.1 \pm 14.6$ & $116.3 \pm 13.9$ & 0.429 \\
\hline DBP (mmHg) & $67.7 \pm 12.0$ & $64.1 \pm 14.6$ & $64.3 \pm 10.7$ & $74.1 \pm 13.2$ & $71.0 \pm 1.7$ & 0.333 \\
\hline Pulse (/min) & $75.1 \pm 9.8$ & $76.9 \pm 13.3$ & $77.6 \pm 8.7$ & $79.6 \pm 9.0$ & $78.0 \pm 7.0$ & 0.968 \\
\hline $\mathrm{SpO}_{2}(\%)$ & $92.8 \pm 4.4$ & $92.7 \pm 8.4$ & $95.0 \pm 2.9$ & $94.8 \pm 2.3$ & $92.3 \pm 5.7$ & 0.167 \\
\hline \multicolumn{7}{|l|}{ Patients' history } \\
\hline Hypertension & $10(28.6 \%)$ & $1(16.7 \%)$ & $4(30.8 \%)$ & $4(36.4 \%)$ & $1(20.0 \%)$ & 0.812 \\
\hline Dyslipidemia & $5(14.3 \%)$ & $0(0 \%)$ & $2(15.4 \%)$ & $2(18.2 \%)$ & $1(20.0 \%)$ & 0.733 \\
\hline Diabetes mellitus & $3(8.6 \%)$ & $0(0 \%)$ & $0(0 \%)$ & $3(27.3 \%)$ & $0(0 \%)$ & 0.67 \\
\hline Acute PE & $8(22.9 \%)$ & $1(16.7 \%)$ & $5(38.5 \%)$ & $2(18.2 \%)$ & $0(0 \%)$ & 0.315 \\
\hline \multicolumn{7}{|l|}{ Laboratory data } \\
\hline $\mathrm{Hb}(\mathrm{g} / \mathrm{dl})$ & $13.8 \pm 2.3$ & $12.7 \pm 2.6$ & $13.7 \pm 2.0$ & $13.9 \pm 2.3$ & $15.2 \pm 2.6$ & 0.407 \\
\hline AST (IU/l) & $23.4 \pm 8.9$ & $19.2 \pm 3.5$ & $25.7 \pm 10.9$ & $22.7 \pm 8.6$ & $23.8 \pm 9.0$ & 0.625 \\
\hline ALT (IU/l) & $20.1 \pm 10.9$ & $15.0 \pm 5.1$ & $23.9 \pm 14.4$ & $20.2 \pm 8.0$ & $15.8 \pm 9.5$ & 0.332 \\
\hline LDH (IU/l) & $215.1 \pm 44.2$ & $178.3 \pm 33.8$ & $229.4 \pm 46.1$ & $216.0 \pm 29.4$ & $220.4 \pm 62.4$ & 0.13 \\
\hline$\gamma \mathrm{GTP}(\mathrm{IU} / \mathrm{l})$ & $44.7 \pm 38.5$ & $23.0 \pm 9.4$ & $48.5 \pm 27.8$ & $54.5 \pm 60.0$ & $39.2 \pm 10.7$ & 0.198 \\
\hline $\operatorname{HbA1c}(\%)$ & $6.0 \pm 0.6$ & $5.9 \pm 0.2$ & $5.9 \pm 0.6$ & $6.2 \pm 0.9$ & $6.1 \pm 0.5$ & 0.564 \\
\hline eGFR $\left(\mathrm{ml} / \mathrm{min} / 1.73 \mathrm{~m}^{2}\right)$ & $67.8 \pm 16.4$ & $70.4 \pm 14.7$ & $65.7 \pm 14.4$ & $68.6 \pm 21.7$ & $68.6 \pm 13.8$ & 0.946 \\
\hline $\mathrm{BNP}(\mathrm{pg} / \mathrm{ml})$ & $127.2 \pm 184.9$ & $33.1 \pm 35.5$ & $46.5 \pm 56.2$ & $174.9 \pm 253.4$ & $345.0 \pm 138.0$ & 0.02 \\
\hline \multicolumn{7}{|l|}{ Hemodynamics } \\
\hline Mean PAP (mmHg) & $37.2 \pm 10.6$ & $28.8 \pm 7.0$ & $35.3 \pm 8.2$ & $42.1 \pm 12.9$ & $41.6 \pm 7.8$ & 0.062 \\
\hline PVR (Wood Unit) & $8.2 \pm 4.7$ & $4.4 \pm 1.4$ & $6.8 \pm 2.4$ & $10.1 \pm 6.0$ & $12.1 \pm 4.8$ & 0.010 \\
\hline $\mathrm{CI}\left(1 / \mathrm{min} / \mathrm{m}^{2}\right)$ & $2.3 \pm 0.7$ & $2.8 \pm 1.0$ & $2.4 \pm 0.5$ & $2.3 \pm 0.7$ & $1.7 \pm 0.2$ & 0.036 \\
\hline $\mathrm{RAP}(\mathrm{mmHg})$ & $6.0 \pm 3.0$ & $5.0 \pm 2.5$ & $5.8 \pm 3.2$ & $5.7 \pm 3.1$ & $8.2 \pm 2.2$ & 0.283 \\
\hline $\mathrm{SvO}_{2}(\%)$ & $62.9 \pm 8.8$ & $66.2 \pm 6.6$ & $66.5 \pm 3.8$ & $60.7 \pm 10.2$ & $54.5 \pm 12.0$ & 0.039 \\
\hline \multicolumn{7}{|l|}{ Medication } \\
\hline DOAC & $15(42.9 \%)$ & $1(16.7 \%)$ & $5(38.5 \%)$ & $6(54.5 \%)$ & $3(60.0 \%)$ & 0.392 \\
\hline Warfarin & $20(57.1 \%)$ & $5(83.3 \%)$ & $8(61.5 \%)$ & $5(45.5 \%)$ & $2(40.0 \%)$ & 0.392 \\
\hline Riociguat & $21(60.0 \%)$ & $6(100.0 \%)$ & $5(38.5 \%)$ & $8(72.7 \%)$ & $2(40.0 \%)$ & 0.044 \\
\hline \multicolumn{7}{|l|}{ RV echo parameters } \\
\hline TAPSE $(\mathrm{mm})$ & $18.7 \pm 4.8$ & $20.7 \pm 1.7$ & $19.7 \pm 4.6$ & $18.2 \pm 6.3$ & $14.9 \pm 2.2$ & 0.093 \\
\hline$S^{\prime}(\mathrm{cm} / \mathrm{s})$ & $11.9 \pm 3.1$ & $13.6 \pm 3.1$ & $12.8 \pm 1.7$ & $11.1 \pm 4.1$ & $9.5 \pm 0.9$ & 0.018 \\
\hline RVFAC (\%) & $33.5 \pm 13.9$ & $42.3 \pm 3.9$ & $36.9 \pm 9.1$ & $31.4 \pm 19.0$ & $18.6 \pm 3.8$ & 0.002 \\
\hline RV-MPI & $0.4 \pm 0.16$ & $0.26 \pm 0.1$ & $0.36 \pm 0.1$ & $0.4 \pm 0.1$ & $0.64 \pm 0.2$ & 0.003 \\
\hline Pericardial effusion & $10(28.6 \%)$ & $1(16.7 \%)$ & $4(30.8 \%)$ & $3(27.3 \%)$ & $2(40.0 \%)$ & 0.855 \\
\hline
\end{tabular}

Data are presented as mean $\pm \mathrm{SD}$ or $n(\%)$

$B M I$ body mass index, $S B P$ systolic blood pressure, $D B P$ diastolic blood pressure, $S p O_{2}$ oxygen saturation, Acute PE acute pulmonary embolism, $H b$ hemoglobin, $A S T$ aspartate aminotransferase, $A L T$ alanine aminotransferase, $L D H$ lactate dehydrogenase, $\gamma G T P \gamma$-glutamyl transferase, $e G F R$ estimated glomerular filtrating ratio, $B N P$ brain natriuretic peptide, mean $P A P$ mean pulmonary artery pressure, $C I$ cardiac index, $P V R$ pulmonary vascular resistance, $R A P$ right atrial pressure, $\mathrm{SvO}_{2}$ mixed venous oxygen saturation, DOAC direct oral anticoagulant. TAPSE tricuspid annular plane systolic excursion, $S^{\prime}$ tissue Doppler-derived tricuspid lateral annular systolic velocity, $R V F A C$ right ventricular fractional area change, $R V$-MPI right ventricular myocardial performance index 
Fig. 1 A comparison of the hemodynamics [mean pulmonary artery pressure (PAP), cardiac index (CI), pulmonary vascular resistance (PVR), right atrial pressure (RAP), and mixed venous oxygen saturation $\left(\mathrm{SvO}_{2}\right)$ ] according to the RV dysfunction score. The mean PAP, CI, PVR, and $\mathrm{SvO}_{2}$ were significantly worsening as the RV dysfunction score increased $(p=0.01, p=0.009, p=0.001$, $p=0.039$, respectively). The right atrial pressure showed a considerable trend toward significance $(p=0.062)$
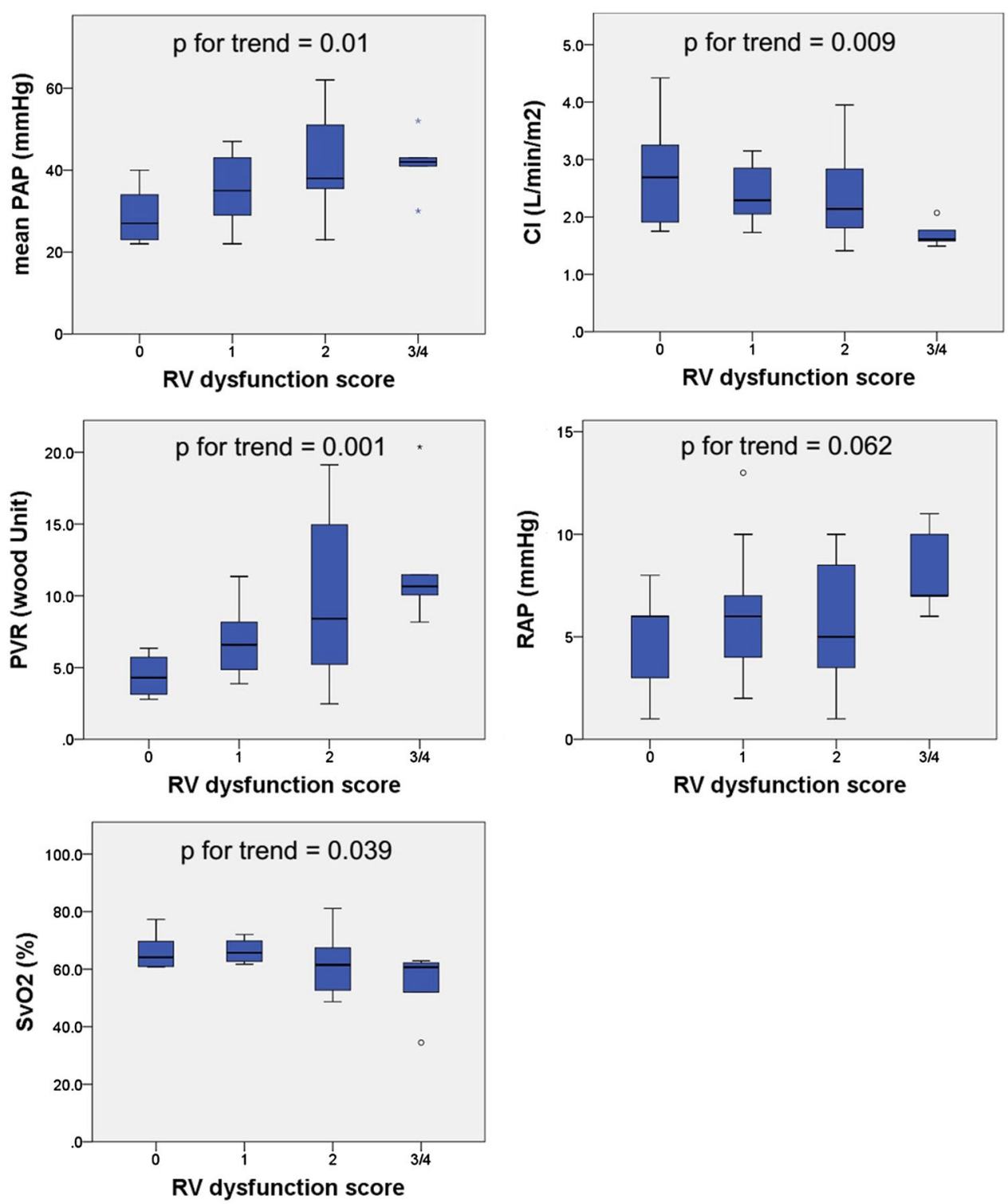

echocardiographic parameters and hemodynamics or RV function assessed by MRI [19-21], suggesting the usefulness of echocardiography.

$\mathrm{RV}$ morphology is complicated, and accurate volumetric assessment with two-dimensional echocardiography is difficult. Therefore, we should be careful in assessing the parameters of echocardiographic RV functions. In the present study, both RV-MPI and RVFAC favorably reflected the hemodynamics in patients with CTEPH. Previously, Amano et al. reported that RV-MPI is a surrogate marker for the right ventricular ejection fraction (RVEF) assessed by MRI in patients with CTEPH [22]. RV-MPI is an index that combines RV systolic and diastolic function to evaluate RV function. Considering that the mean PAP was relatively high in our cohort $(36.9 \pm 12.0 \mathrm{mmHg})$, not only systolic function but also diastolic function would be impaired. Therefore, we speculated that RV-MPI showed a good correlation with hemodynamics in our cohort. As for exercise capacity, which was also important factor in previous report [23], some relationship was confirmed, although there was no statistically difference. RVFAC is known to reflect RV function; RVFAC has been shown to have a good correlation with RVEF measured by MRI and to be an independent predictor of mortality after pulmonary emboli [24]. RVFAC was reported to provide relevant clinical and prognostic information of pulmonary arterial hypertension when combined with the result obtained by CPET [25]. In accordance with these results, RVFAC correlated with hemodynamic status and exercise capacity the most, implying that RVFAC would be the best parameter among the four RV function parameters.

In contrast, TAPSE and $S^{\prime}$ did not show strong correlations with hemodynamics and exercise capacity. Kind et al. 
Fig. 2 A comparison of the exercise capacity [6-min walk distance (6MWD), and peakVO, $\mathrm{VE} / \mathrm{VCO}_{2}$ slope)], symptom (WHO functional class), and plasma BNP level according to RV dysfunction score. All parameters showed significant deteriorating trend as the RV function score increased $(p=0.046, p=0.016, p=0.031$, $p=0.026$, and $p=0.005$, respectively)
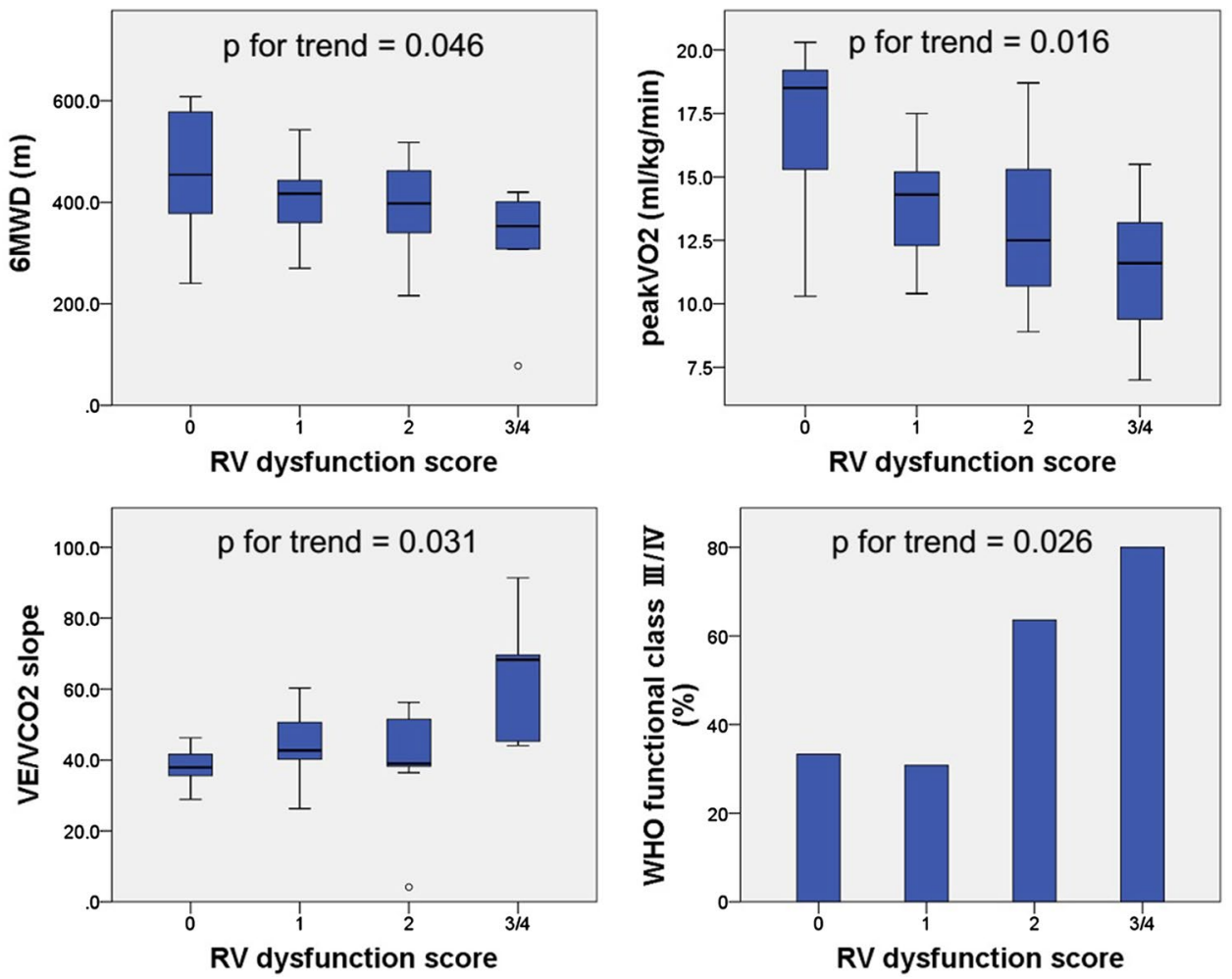

reported that transverse measurement rather than longitudinal assessment, such as TAPSE and $S^{\prime}$, reflects RVEF in pulmonary hypertension [26], In addition, TAPSE and $S^{\prime}$ could be affected by RV enlargement and clockwise rotation of the apex of the heart [27]. Therefore, RV enlargement in patients with CTEPH might overestimate TAPSE and $S^{\prime}$. But, actually TAPSE showed significant correlation with 6MWD $(r=0.340, p=0.049)$ in our study (data not shown). There is also another report that resting TAPSE and $S^{\prime}$ also showed moderate correlations with peak $\mathrm{VO}_{2}$ [28], and $\mathrm{RV} S^{\prime}<10.5 \mathrm{~cm} / \mathrm{s}$ raise suspicion for worse response to vasodilators in patients with CTD-PAH [29]. Although both TAPSE and $S^{\prime}$ are used for the evaluation of the RV longitudinal movement, there are few reports clearly representing the difference between TAPSE and $S^{\prime}$ in patients with CTEPH. Indeed, TAPSE is the index of distance of RV longitudinal movement, while $S^{\prime}$ is that of speed of RV longitudinal movement. Considering relatively low correlation coefficient between TAPSE and $S^{\prime}$ shown in Table 3 ( $r=0.603$ ), we finally proposed to evaluate comprehensive RV function by adding both TAPSE and $S^{\prime}$ into RV dysfunction score in our study.

The 2015 ESC/ERS guidelines recommended the comprehensive prognostic evaluation and risk assessment for PAH patients since the single variable provides insufficient prognostic information [30]. However, the risk predictor in CTEPH patients was not shown previously as far as we know. Considering that the pathophysiology of CTEPH is caused not only by the obstruction of pulmonary artery by fibrotic transformation of pulmonary artery clots, but also by vascular remodeling in the microvasculature similar to $\mathrm{PAH}$ [31], a comprehensive risk assessment should also be done in patients with CTEPH at the time of initial risk assessment, treatment response assessment, and clinical worsening 


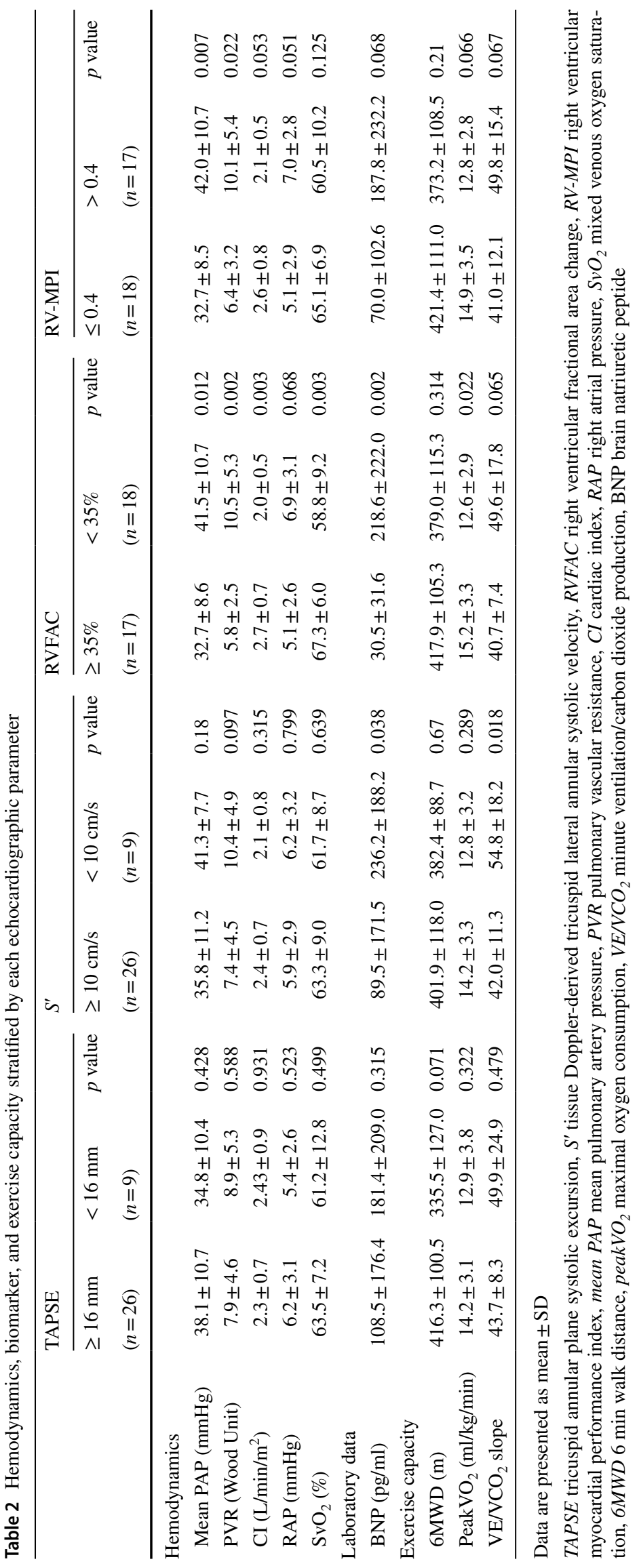


Table 3 Correlation matrix for four RV echocardiographic parameters

\begin{tabular}{lllll}
\hline & TAPSE & $S^{\prime}$ & RVFAC & RV-MPI \\
\hline TAPSE & $r=1$ & & & \\
$S^{\prime}$ & $r=0.603$ & $r=1$ & & \\
& $p<0.001$ & & & \\
RVFAC & $r=-0.226$ & $r=-0.108$ & $r=1$ & \\
& $p=0.192$ & $p=0.538$ & & \\
RV-MPI & $r=-0.097$ & $r=-0.035$ & $r=-0.461$ & $r=1$ \\
& $p=0.579$ & $p=0.841$ & $p=0.005$ & \\
\hline
\end{tabular}

TAPSE tricuspid annular plane systolic excursion, $S^{\prime}$ tissue Dopplerderived tricuspid lateral annular systolic velocity, RVFAC right ventricular fractional area change, $R V-M P I$ right ventricular myocardial performance index

assessment [32]. Therefore, we compared the RV dysfunctional score with the variables recommended in the PAH guidelines for the evaluation of the CTEPH patients. The results showed that the RV dysfunction score showed good correlation with each important parameter of PAH. Thus, we concluded the RV dysfunction score was useful for evaluating the CTEPH prognosis.

The strength of the RV dysfunction score is that it can evaluate the patient's status non-invasively and comprehensively. It could be useful not only for assessing RV function during the course of CTEPH treatment but also for predicting CTEPH prognosis.

Our study had several limitations. First, this study was single-center study and the sample size was relatively small. Because of few clinical events, we could not examine a relationship between the RV dysfunction score and prognosis in our cohort. Second, we have not determined whether this RV dysfunction score is suitable for patients with other types of pulmonary hypertension. Third, as intra-observer variability was not assessed, and the reproducibility of RV echocardiographic parameters could not be evaluated. Fourth, as we did not correct weighting, we could not prove each of the four RV echocardiographic parameters had equal value. Finally, we did not measure speckle-tracking strain, which has been used recently as a useful index for the assessment of RV function [33-35], RV dyssynchrony [36], and 3-dimensional assessment [37].

In conclusion, we proposed an RV dysfunction score using the four RV echocardiographic parameters (TAPSE $<16 \mathrm{~mm}, S^{\prime}<10 \mathrm{~cm} / \mathrm{s}, \mathrm{RVFAC}<35 \%$, and RVMPI $>0.4$ ) in patients with CTEPH and demonstrated that the RV dysfunction score represents patients' characteristics on admission and hemodynamics. This RV dysfunction score could be a simple and useful scoring system providing a good estimation for hemodynamics when treating patients with CTEPH before catheterization.
Acknowledgements This study was supported in part by Grant-in-Aid for Scientific Research (C) (Nos. 26461106 and 15K09074) by Japan Society for the Promotion of Science. We express our sincere appreciation to all the patients, collaborating physicians and other medical staff for their important contributions to the present study.

\section{Compliance with ethical standards}

Conflict of interest Takahisa Kondo, Naoki Okumura and Shiro Adachi belong to the endowed department by Actelion Pharmaceuticals Japan, Ltd.

Open Access This article is distributed under the terms of the Creative Commons Attribution 4.0 International License (http://creativeco mmons.org/licenses/by/4.0/), which permits unrestricted use, distribution, and reproduction in any medium, provided you give appropriate credit to the original author(s) and the source, provide a link to the Creative Commons license, and indicate if changes were made.

\section{References}

1. Lang IM, Madani M (2014) Update on chronic thromboembolic pulmonary hypertension. Circulation 130:508-518

2. Jenkins D, Mayer E, Screaton N (2012) State-of-the-art chronic thromboembolic pulmonary hypertension diagnosis and management. Eur Respir Rev 21:32-39

3. Tei C, Dujardin KS, Hodge DO, Bailey KR, McGoon MD, Tajik AJ, Seward JB (1996) Doppler echocardiographic index for assessment of global right ventricular function. J Am Soc Echocardiogr 9:838-847

4. Kaul S, Tei C, Hopkins JM, Shah PM (1984) Assessment of right ventricular function using two-dimensional echocardiography. Am Heart J 107:526-531

5. Alam M, Wardell J, Andersson E, Samad BA, Nordlander R (1999) Characteristics of mitral and tricuspid annular velocities determined by pulsed wave Doppler tissue imaging in healthy subjects. J Am Soc Echocardiogr 12:618-628

6. Rudski LG, Lai WW, Afilalo J, Hua L, Handschumacher MD, Chandrasekaran K, Solomon SD, Louie EK, Schiller NB (2010) Guidelines for the echocardiographic assessment of the right heart in adults: a report from the American Society of Echocardiography endorsed by the European Association of Echocardiography, a registered branch of the European Society of Cardiology, and the Canadian Society of Echocardiography. J Am Soc Echocardiogr 23:685-713

7. Gerges C, Skoro-Sajer N, Lang IM (2014) Right ventricle in acute and chronic pulmonary embolism (2013 Grover Conference series). Pulm Circ 4:378-386

8. Kukulski T, Hubbert L, Arnold M, Wranne B, Hatle L, Sutherland GR (2000) Normal regional right ventricular function and its change with age: a Doppler myocardial imaging study. J Am Soc Echocardiogr 13:194-204

9. Haddad F, Hunt SA, Rosenthal DN (2008) Right ventricular function in cardiovascular disease, part I: anatomy, physiology, aging, and functional assessment of the right ventricle. Circulation 117:1436-1448

10. Haddad F, Doyle R, Murphy DJ, Hunt SA (2008) Right ventricular function in cardiovascular disease, part II: pathophysiology, clinical importance, and management of right ventricular failure. Circulation 117:1717-1731

11. Delcroix M, Noordegraaf AV, Fadel E, Lang I, Simonneau G, Naeije R (2013) Vascular and right ventricular remodelling in 
chronic thromboembolic pulmonary hypertension. Eur Respir J 41:224-232

12. Simonneau G, Torbicki A, Dorfmuller P, Kim N (2017) The pathophysiology of chronic thromboembolic pulmonary hypertension. Eur Respir Rev 26:160112

13. Galiè N, Hoeper MM, Humbert M, Torbicki A, Vachiery JL, Barbera JA, Beghetti M, Corris P, Gaine S, Gibbs JS, GomezSanchez MA, Jondeau G, Klepetko W, Opitz C, Peacock A, Rubin L, Zellweger M, Simonneau G (2009) Guidelines for the diagnosis and treatment of pulmonary hypertension: the Task Force for the Diagnosis and Treatment of Pulmonary Hypertension of the European Society of Cardiology (ESC) and the European Respiratory Society (ERS), endorsed by the International Society of Heart and Lung Transplantation (ISHLT). Eur Heart J 30:2493-2537

14. Vonk-Noordegraaf A, Souza R (2012) Cardiac magnetic resonance imaging: what can it add to our knowledge of the right ventricle in pulmonary arterial hypertension? Am J Cardiol 110:25S-31S

15. Koch JA, Poll LW, Godehardt E, Korbmacher B, Jung G, Modder U (2001) In vitro determination of cardiac ventricular volumes using MRI at $1.0 \mathrm{~T}$ in a porcine heart model. Int $\mathrm{J}$ Cardiovasc Imaging 17:237-242

16. Peacock AJ, Noordegraaf AV (2013) Cardiac magnetic resonance imaging in pulmonary arterial hypertension. Eur Respir Rev 22:526-534

17. Nakano Y, Okumura N, Adachi S, Shimokata S, Tajima F, Kamimura Y, Murohara T, Kondo T (2017) Left ventricular enddiastolic dimension and septal e' are predictors of cardiac index at rest, while tricuspid annular plane systolic excursion is a predictor of peak oxygen uptake in patients with pulmonary hypertension. Heart Vessels. https://doi.org/10.1007/s00380-017-1086-0

18. Hioka T, Kaga S, Mikami T, Okada K, Murayama M, Masauzi N, Nakabachi M, Nishino H, Yokoyama S, Nishida M, Iwano H, Sakakibara M, Yamada S, Tsutsui H (2017) Overestimation by echocardiography of the peak systolic pressure gradient between the right ventricle and right atrium due to tricuspid regurgitation and the usefulness of the early diastolic transpulmonary valve pressure gradient for estimating pulmonary artery pressure. Heart Vessels 32:833-842

19. Pavlicek M, Wahl A, Rutz T, de Marchi SF, Hille R, Wustmann K, Steck H, Eigenmann C, Schwerzmann M, Seiler C (2011) Right ventricular systolic function assessment: rank of echocardiographic methods vs. cardiac magnetic resonance imaging. Eur J Echocardiogr 12:871-880

20. Yang T, Liang Y, Zhang Y, Gu Q, Chen G, Ni XH, Lv XZ, Liu ZH, Xiong CM, He JG (2013) Echocardiographic parameters in patients with pulmonary arterial hypertension: correlations with right ventricular ejection fraction derived from cardiac magnetic resonance and hemodynamics. PLoS One 8:e71276

21. Tousignant C, Kim H, Papa F, Mazer CD (2012) Evaluation of TAPSE as a measure of right ventricular output. Can J Anaesth 59:376-383

22. Amano H, Abe S, Hirose S, Waku R, Masuyama T, Sakuma M, Toyoda S, Taguchi I, Inoue T, Tei C (2017) Comparison of echocardiographic parameters to assess right ventricular function in pulmonary hypertension. Heart Vessels 32:1214-1219

23. Kasikcioglu E, Oflaz H, Akhan H, Kayserilioglu A (2005) Right ventricular myocardial performance index and exercise capacity in athletes. Heart Vessels 20:147-152

24. Anavekar NS, Gerson D, Skali H, Kwong RY, Yucel EK, Solomon SD (2007) Two-dimensional assessment of right ventricular function: an echocardiographic-MRI correlative study. Echocardiography 24:452-456

25. Badagliacca R, Papa S, Valli G, Pezzuto B, Poscia R, Manzi G, Giannetta E, Sciomer S, Palange P, Naeije R, Fedele F, Vizza CD (2016) Echocardiography combined with cardiopulmonary exercise testing for the prediction of outcome in idiopathic pulmonary arterial hypertension. Chest 150:1313-1322
26. Kind T, Mauritz GJ, Marcus JT, van de Veerdonk M, Westerhof N, Vonk-Noordegraaf A (2010) Right ventricular ejection fraction is better reflected by transverse rather than longitudinal wall motion in pulmonary hypertension. J Cardiovasc Magn Reson 12:35

27. Motoji Y, Tanaka H, Fukuda Y, Sano H, Ryo K, Sawa T, Miyoshi T, Imanishi J, Mochizuki Y, Tatsumi K, Matsumoto K, Emoto N, Hirata K (2016) Association of apical longitudinal rotation with right ventricular performance in patients with pulmonary hypertension: insights into overestimation of tricuspid annular plane systolic excursion. Echocardiography 33:207-215

28. Sharma T, Lau EM, Choudhary P, Torzillo PJ, Munoz PA, Simmons LR, Naeije R, Celermajer DS (2015) Dobutamine stress for evaluation of right ventricular reserve in pulmonary arterial hypertension. Eur Respir J 45:700-708

29. Liu YT, Li MT, Fang Q, Tian Z, Guo XX, Zhu WL, Wang Q, Zeng XF (2012) Right-heart function related to the results of acute pulmonary vasodilator testing in patients with pulmonary arterial hypertension caused by connective tissue disease. J Am Soc Echocardiogr 25:274-279

30. Galiè N, Humbert M, Vachiery JL, Gibbs S, Lang I, Torbicki A, Simonneau G, Peacock A, Vonk Noordegraaf A, Beghetti M, Ghofrani A, Gomez Sanchez MA, Hansmann G, Klepetko W, Lancellotti P, Matucci M, McDonagh T, Pierard LA, Trindade PT, Zompatori M, Hoeper M, Aboyans V, Vaz Carneiro A, Achenbach S, Agewall S, Allanore Y, Asteggiano R, Paolo Badano L, Albert Barberà J, Bouvaist H, Bueno H, Byrne RA, Carerj S, Castro G, Erol Ç, Falk V, Funck-Brentano C, Gorenflo M, Granton J, Iung B, Kiely DG, Kirchhof P, Kjellstrom B, Landmesser U, Lekakis J, Lionis C, Lip GY, Orfanos SE, Park MH, Piepoli MF, Ponikowski P, Revel MP, Rigau D, Rosenkranz S, Völler H, Luis Zamorano J (2016) 2015 ESC/ERS Guidelines for the diagnosis and treatment of pulmonary hypertension: the Joint Task Force for the Diagnosis and Treatment of Pulmonary Hypertension of the European Society of Cardiology (ESC) and the European Respiratory Society (ERS): Endorsed by: Association for European Paediatric and Congenital Cardiology (AEPC), International Society for Heart and Lung Transplantation (ISHLT). Eur Heart J 37:67-119

31. Galiè N, Kim NH (2006) Pulmonary microvascular disease in chronic thromboembolic pulmonary hypertension. Proc Am Thorac Soc 3:571-576

32. Weatherald J, Sitbon O, Humbert M (2017) Validation of a risk assessment instrument for pulmonary arterial hypertension. Eur Heart J. https://doi.org/10.1093/eurheartj/ehx301

33. Motoji Y, Tanaka H, Fukuda Y, Ryo K, Emoto N, Kawai H, Hirata K (2013) Efficacy of right ventricular free-wall longitudinal speckle-tracking strain for predicting long-term outcome in patients with pulmonary hypertension. Circ J 77:756-763

34. Fukuda Y, Tanaka H, Sugiyama D, Ryo K, Onishi T, Fukuya H, Nogami M, Ohno Y, Emoto N, Kawai H, Hirata K (2011) Utility of right ventricular free wall speckle-tracking strain for evaluation of right ventricular performance in patients with pulmonary hypertension. J Am Soc Echocardiogr 24:1101-1108

35. Atsumi A, Ishizu T, Kameda Y, Yamamoto M, Harimura Y, Machino-Ohtsuka T, Kawamura R, Enomoto M, Seo Y, Aonuma K (2013) Application of 3-dimensional speckle tracking imaging to the assessment of right ventricular regional deformation. Circ J 77:1760-1768

36. Murata M, Tsugu T, Kawakami T, Kataoka M, Minakata Y, Endo J, Tsuruta H, Itabashi Y, Maekawa Y, Fukuda K (2017) Right ventricular dyssynchrony predicts clinical outcomes in patients with pulmonary hypertension. Int J Cardiol 228:912-918

37. Inaba $\mathrm{T}$, Yao A, Nakao $\mathrm{T}$, Hatano $\mathrm{M}$, Maki $\mathrm{H}$, Imamura $\mathrm{T}$, Shiga T, Yamazaki T, Sonoda M, Kinugawa K, Shiota T, Suzuki J, Takenaka K, Hirata Y, Nagai R (2013) Volumetric and functional assessment of ventricles in pulmonary hypertension on 3-dimensional echocardiography. Circ J 77:198-206 